Tropical Journal of Pharmaceutical Research October 2019; 18 (10): 2075-2079

ISSN: $1596-5996$ (print); 1596-9827 (electronic)

(c) Pharmacotherapy Group, Faculty of Pharmacy, University of Benin, Benin City, 300001 Nigeria.

Original Research Article

http://dx.doi.org/10.4314/tjpr.v18i10.11

\title{
Effect of Atractylodes macrocephala extract on chronic heart failure in rats
}

\author{
Huang Kang, Lu Shi-juan*, Zhong Jiang-hua, Wu Miao, Zhang Wei, Li Qiang, \\ Xiang Qun, Zhou Yi-lei, Wang Liu \\ Cardiology Department, Central South University Xiangya School of Medicine Affiliated Haikou Hospital, Haikou 570208, \\ Hainan Province, China
}

*For correspondence: Email: lushijuan133@126.com; Tel: +86-8986-6151132

Sent for review: 14 March 2019

Revised accepted: 23 September 2019

\begin{abstract}
Purpose: To investigate the effect of Atractylodes macrocephala extract (AME) on oxidative stress and hemodynamics in chronic congestive heart failure (CHF) rats.

Methods: After Sprague Dawley (SD) rats were successfully establised into CHF, they were randomly divided into normal control group, negative control group, captopril group, as well as 1.4, 2.8 and 5.6 $\mathrm{g} / \mathrm{kg}$ of AME groups, and treated with drugs for 4 weeks. Hemodynamic function, whole heart weight index, blood creatinine kinase (CK), superoxide dismutase (SOD), malondialdehyde (MDA), nitric oxide (NO), nitric oxide synthase (NOS) were measured.

Results: Compared with the normal control group, arterial systolic pressure (SBP)(83.12 \pm 16.21 $\mathrm{mmHg})$, diastolic pressure $(D B P,(75.16 \pm 20.18 \mathrm{mmHg})$, mean arterial pressure (MAP 76.32 \pm 13.43 $\mathrm{mmHg}$ ), heart rate (HR 353.25 \pm 36.34 beats/min), left ventricular systolic peak (LVSP 101.24 \pm 16.13 $\mathrm{mmHg})$, and left ventricular pressure change rate $(d p / d t \max )$ significantly decreased $(p<0.05)$, while left ventricular end diastolic pressure (LVEDP $(22.13 \pm 1.57 \mathrm{mmHg})$, whole heart weight index $(2.74 \pm$ $0.16 \mathrm{mg} / \mathrm{g})$, blood CK (0.93 $\pm 0.14 \mathrm{U} / \mathrm{mL}), M D A(19.13 \pm 2.26 \mathrm{nmol} / \mathrm{mL}), \mathrm{NO}(34.21 \pm 3.16 \mathrm{umo} / \mathrm{L})$, and NOS $(42.13 \pm 3.24 \mathrm{U} / \mathrm{mL})$ increased significantly increased in the negative control group $(p<0.05)$. High dose AME significantly improved hemodynamic function, lowered MDA $(8.75 \pm 2.09 \mathrm{nmol} / \mathrm{mL})$ and NO $(22.14 \pm 3.27$ umol/L) levels $(p<0.05)$, and also decreased CK $(0.57 \pm 0.31 \mathrm{U} / \mathrm{mL})$ and NOS $(24.24$ $\pm 3.38 \mathrm{U} / \mathrm{mL})$ in CHF rats $(p<0.05)$.

Conclusion: AME significantly improve adriamycin-induced chronic congestive heart failure in rats, which could be used for the therapeutic manaement of chronic congestive heart failure in future.
\end{abstract}

Keywords: Atractylodes macrocephala, Chronic heart failure, Hemodynamic function, Oxidative stress

This is an Open Access article that uses a fund-ing model which does not charge readers or their institutions for access and distributed under the terms of the Creative Commons Attribution License (http://creativecommons.org/licenses/by/4.0) and the Budapest Open Access Initiative (http://www.budapestopenaccessinitiative.org/read), which permit unrestricted use, distribution, and reproduction in any medium, provided the original work is properly credited.

Tropical Journal of Pharmaceutical Research is indexed by Science Citation Index (SciSearch), Scopus, International Pharmaceutical Abstract, Chemical Abstracts, Embase, Index Copernicus, EBSCO, African Index Medicus, JournalSeek, Journal Citation Reports/Science Edition, Directory of Open Access Journals (DOAJ), African Journal Online, Bioline International, Open-J-Gate and Pharmacy Abstracts

\section{INTRODUCTION}

Chronic heart failure (CHF) is a common, complex clinical syndrome that arises from structural or functional cardiac disorder, including changes in electrophysiology, contraction, and energy metabolism [1]. Heart failure (HF) is becoming a serious disease with an incidence approaching 1 percent of the population over 65 years of age in developed countries [2]. In China, it has been reported that the prevalence of $\mathrm{HF}$ in 
the adult population from ten provinces was 0.9 $\%$ [3]. The prognosis for CHF is poor and there are few therapeutic options. HF is even worse than many types of cancer [4]. Furthermore, it is an increased hospitalization burden, thus making it a global public health problem.

The most effective and commonly used drugs for treatment of $\mathrm{HF}$ are angiotensin-converting enzyme (ACE) inhibitors, $\beta$-adrenoceptor blockers, and digitalis [5-7]. The American Heart Association (AHA) and European Society of Cardiology (ESC) have issued and updated the guidelines for diagnosis and management of $\mathrm{CHF}$ [2]. However, HF is still a leading cause of death worldwide [8].

Therefore, it is necessary to seek novel effective drugs for HF. Traditional Chinese medicine has gained popularity in the treatment of complex multifactor diseases by targeting multiple pathways to improve therapeutic efficacy and reduces drug-related side effects and drug resistance. TCMs such as Shengmai [9], Sini decoction [10], Shuanglong formula [11], and Huangqi injection [12] have potential therapeutic effects on cardiovascular diseases.

Atractylodes macrocephala extract (AME) has the effects of promoting blood circulation and removing blood stasis, tonifying the blood and arresting bleeding, and alleviating pain [13,14]. However, the effect study of AME for treatment of cardiovascular diseases has not been reported yet. In this study, the effect of AME on chronic $\mathrm{CHF}$ was studied in adriamycin-induced $\mathrm{CHF}$ rats.

\section{EXPERIMENTAL}

\section{Preparation of AME}

The plant material Atractylodes macrocephala collected from Zhunyi City, Guizhou Province in China in October 2017. Taxonomic identification of the plant was performed by Professor LanWang of Hainan Medical University, China. A voucher specimen (no. PRLE 201710005) was deposited in the herbarium of College of Pharmacy, Hainan Medical University, China for future reference.

The herbal samples Atractylodes macrocephala were dried in an oven. AME was obtained by steeping the dried Atractylodes macrocephala in water at $60{ }^{\circ} \mathrm{C}$. It was repeated for three times and each for one hour. Then it was putted in an oven and then freeze-dried. The yield was 66.67 $\%$.

\section{Animals}

SD male rats, weighing $180 \pm 20 \mathrm{~g}$, were purchased from the Experimental Animal Center of Hainan Province (Certificate no. SYXK 20080001). Each rat was raised in single cage, at the environment temperature of $20 \pm 2{ }^{\circ} \mathrm{C}$, and humidity $55-65 \%$. They were free access to food and water. The rat experiment was approved by the Animal Care and Use Committee of Central South University Xiangya School of Medicine Affiliated Haikou Hospital (approval ref no. 20081023) and carried out in compliance with the guidelines of Directive $2010 / 63 / E U$ on the handling of animals used for scientific purposes [15].

\section{Preparation of chronic heart failure rats and treatment}

Sixty SD rats were divided into normal control, negative control, captopril, and 1.4, 2.8 and 5.6 $\mathrm{g} / \mathrm{kg}$ AME groups. There were 10 rats in each group. Normal control rats were treated with intrperitoneal injection of $0.2 \mathrm{~mL}$ saline. Other rats were administered intraperitoneal injection of adriamycin hydrochloride $(2 \mathrm{mg} / \mathrm{kg}$ ) once a week. It was repeated 6 times. Six weeks later, 2 rats were randomly selected from the survived rats with heart failure for detection of the cardiac function. Administration of drugs lasted from the 7th week after CHF was established. The rats in normal control and negative control groups were intragastrically administered $2 \mathrm{~mL}$ saline, once a day; rats of the AME group were administrated intragastrically with AME. The dosage were 1.4, 2.8 or $5.6 \mathrm{~g} / \mathrm{kg}$, respectively, once a day. The rats in the captopril group were administrated with captopril, (80 mg/kg), once each day. The administration lasted for 4 weeks.

\section{Determination of cardiac function and hemodynamics}

Twenty four hours after the last intragastrical administration, the rats were anesthetized by intraperitoneal injection of $20 \%$ urethane solution and were fixed on a table in a spinal position. The right common carotid artery was separated with a ventricular canula (cardiac catheter I mm in diameter), which was connected with the Biopac multichannel physiological sign collection and processing system via a pressure transducer; SBP, DBP, MAP, HR were recorded. The cardiac catheter was slowly pushed, and at the same time the pressure oscilloscope was observed. After stabilization for $3 \mathrm{~min}$, the LVSP, LVEDP,$+d p / d t_{\max }$, and - dp/dt $\mathrm{dmax}_{\text {were }}$ recorded. For the hemodynamic indices, 5 sections were respectively taken for calculation of the mean 
value. Then, $10 \mathrm{~mL}$ blood was taken from the abdominal aorta, $5 \mathrm{~mL}$ added to $200 \mathrm{uL}$ EDTA; 5 $\mathrm{mL}$ (without anti-coagulant) was centrifuged at $3000 \mathrm{rpm}$ for $15 \mathrm{~min}$. The plasma and serum samples were kept at $-20{ }^{\circ} \mathrm{C}$ for other index assay.

\section{Determination of heart weight index (heart weight/weight)}

After hemodynamic assessment and blood sampling, the heart was rapidly detached from the rat body and the blood stain washed with saline with the water on it absorbed with a filter paper. The whole heart was weighed, and the whole heart weight index was calculated. Whole heart weight index $=$ whole heart weight (mg)/body weight (g).

\section{Biochemical tests}

CK, MDA, SOD, NO and NOS in plasma and serum were determined according to the manufacturer's instruction of ELISA kits (Shenzhen Xin Bo Sheng Biological Technology Co., Ltd., Shenzhen, China).

\section{Statistical analysis}

All tests were analyzed using Statistical Product and Service Solutions (SPSS) 16.0 software (SPSS Inc, Illinois, Chicago, USA). Data are expressed as mean \pm standard error of mean (SEM) and were analyzed by one-way analysis of variance (ANOVA) followed by Dunnett's ttest. A value of $p<0.05$ was considered statistically significant.

\section{RESULTS}

\section{Effect of AME on whole heart weight index}

The heart weight index (HWI) in the negative control group was higher than that in the normal control group $(p<0.05)$, indicating that there are myocardial hypertrophy or stasis of blood in the negative control group. Compared with model group, HWI was not significantly changed in the captopril and AME treatment groups (Table 1).

\section{Effect of AME on hemodynamic parameters}

Compared with the normal control group, SBP, DBP, MAP, HR, LVSP, dp/dt $\mathrm{dtax}_{\max }$ were significantly decreased $(p<0.05)$, and LVEDP was significantly increased in the model group $(p<$ $0.01)$. AME significantly improved vasomotoricity and the left ventricular function of the rats with CHF ( $p<0.05)$; while captopril did not have significant effects on vasomotoricity and the left ventricular function of the rats with CHF (Table 2 and Table 3).

Table 1: Heart index of CHF rats $(n=10)$

\begin{tabular}{lcc}
\hline Group & Dose $\mathbf{( g / k g )}$ & HWI $(\mathbf{m g} / \mathbf{g})$ \\
\hline Normal & - & $2.19 \pm 0.25$ \\
Negative control & - & $2.85 \pm 0.19$ \\
Captopril & 0.08 & $2.40 \pm 0.22$ \\
AME-L & 1.4 & $2.64 \pm 0.31$ \\
AME-M & 2.8 & $2.58 \pm 0.28$ \\
AME-H & 5.6 & $2.52 \pm 0.24$ \\
\hline Compared with model group, $p<0.05, p<$ \\
0.01.AME-L: $1.4 \mathrm{~g} / \mathrm{kg}$ of AME, AME-M: $2.8 \mathrm{~g} / \mathrm{kg}$ of \\
AME, AME-H: $5.6 \mathrm{~g} / \mathrm{kg}$ of AME
\end{tabular}

\section{Effect of AME on blood CK, SOD, MDA, NO and NOS}

Compared with the normal control group, $\mathrm{CK}$ and NOS activities, MDA and NO levels were significantly increased $(p<0.01)$, and SOD activity was significantly decreased in the model group $(p<0.01)$. Compared with the model group, blood CK activity, MDA and NO levels were significantly decreased in the captopril group $(p<0.01)$, and MDA and NO levels, NOS activity significantly decreased in the AME group $(p<0.01$, Table 4).

Table 2: Hemodynamic indices of CHF rats $(n=10)$

\begin{tabular}{lccccc}
\hline Group & Dose $(\mathbf{g} / \mathbf{k g})$ & SBP $(\mathbf{m m H g})$ & DBP $(\mathbf{m m H g})$ & MAP $(\mathbf{m m H g})$ & $\begin{array}{c}\text { HR } \\
\text { (beats/min) }\end{array}$ \\
\hline Normal & - & $116.23 \pm 12.31^{*}$ & $109.24 \pm 15.26^{*}$ & $102.16 \pm 15.35^{*}$ & $456.14 \pm 30.36^{*}$ \\
Negative control & - & $83.12 \pm 16.21$ & $75.16 \pm 20.18$ & $76.32 \pm 13.43$ & $353.25 \pm 36.34$ \\
Captopril & 0.08 & $108.18 \pm 22.37$ & $94.23 \pm 34.31$ & $96.24 \pm 23.16$ & $407.21 \pm 45.23$ \\
AME-L & 1.4 & $96.25 \pm 17.24$ & $82.25 \pm 27.35$ & $82.12 \pm 16.27$ & $375.21 \pm 32.11$ \\
AME-M & 2.8 & $103.16 \pm 16.22^{*}$ & $96.24 \pm 18.34$ & $98.21 \pm 13.17$ & $387.33 \pm 30.54$ \\
AME-H & 5.6 & $119.38 \pm 11.42^{* *}$ & $102.12 \pm 17.25^{* *}$ & $109.26 \pm 12.51^{* *}$ & $413.42 \pm 37.31^{*}$
\end{tabular}

Compared with model group, $p<0.05, " p<0.01$.AME-L: $1.4 \mathrm{~g} / \mathrm{kg}$ of AME, AME-M: $2.8 \mathrm{~g} / \mathrm{kg}$ of AME, AME-H: 5.6 $\mathrm{g} / \mathrm{kg}$ of AME 
Table 3: More hemodynamic indices of CHF rats $(n=10)$

\begin{tabular}{|c|c|c|c|c|c|}
\hline Group & $\begin{array}{l}\text { Dose } \\
(\mathrm{g} / \mathrm{kg})\end{array}$ & $\begin{array}{c}\text { LVSP } \\
(\mathrm{mmHg})\end{array}$ & LVEDP (mmHg) & $+d p / d t_{\max }$ & $-d p / d t_{\max }$ \\
\hline Normal & - & $158.15 \pm 12.34$ & $7.56 \pm 1.21$ & $3743.12 \pm 412.25$ & $3853.12 \pm 413.12$ \\
\hline $\begin{array}{l}\text { Negative } \\
\text { control }\end{array}$ & - & $101.24 \pm 16.13$ & $22.13 \pm 1.57$ & $2135.23 \pm 623.36$ & $2534.54 \pm 621.15$ \\
\hline Captopril & 0.08 & $115.12 \pm 32.34$ & $15.83 \pm 2.12$ & $3437.21 \pm 803.15$ & $3324.21 \pm 713.21$ \\
\hline AME-L & 1.4 & $111.16 \pm 15.36$ & $18.14 \pm 1.92$ & $2648.12 \pm 551.08$ & $2546.12 \pm 623.45$ \\
\hline AME-M & 2.8 & $124.25 \pm 13.28^{*}$ & $15.39 \pm 2.86$ & $3058.24 \pm 485.14$ & $3106.54 \pm 512.24$ \\
\hline AME-H & 5.6 & $139.16 \pm 12.16$ & $9.17 \pm 2.51^{\pi}$ & $3472.12 \pm 512.26$ & $3746.22 \pm 507.32$ \\
\hline
\end{tabular}

Table 4: Blood CK, SOD, MDA, NO and NOS of rats $(n=10)$

\begin{tabular}{|c|c|c|c|c|c|c|}
\hline Group & Dose $(\mathbf{g} / \mathbf{k g})$ & CK (U/mL) & SOD (U/mgprot) & MDA (nmol/mL) & NO (umol/L) & $\begin{array}{c}\text { NOS } \\
(\mathrm{U} / \mathrm{mL}) \\
\end{array}$ \\
\hline Normal & - & $0.39 \pm 0.12^{* *}$ & $98.23 \pm 7.21^{\star \star}$ & $5.24 \pm 1.16^{* *}$ & $17.48 \pm 1.55^{* *}$ & $22.35 \pm 3.17^{* *}$ \\
\hline $\begin{array}{l}\text { Negative control } \\
\text { Captopril } \\
\text { AME-L } \\
\text { AME-M } \\
\text { AME-H }\end{array}$ & $\begin{array}{c}- \\
0.08 \\
1.4 \\
2.8 \\
5.6 \\
\end{array}$ & $\begin{array}{c}0.93 \pm 0.14 \\
0.42 \pm 0.13 \\
0.76 \pm 0.21 \\
0.65 \pm 0.24 \\
0.57 \pm 0.31 \\
\end{array}$ & $\begin{array}{l}72.56 \pm 4.12 \\
84.13 \pm 7.56 \\
73.23 \pm 7.12 \\
77.12 \pm 7.42 \\
74.23 \pm 6.58 \\
\end{array}$ & $\begin{array}{l}19.13 \pm 2.26 \\
8.34 \pm 1.67^{-1} \\
14.12 \pm 2.32 \\
11.45 \pm 2.28 \\
8.75 \pm 2.09^{\pi \pi}\end{array}$ & $\begin{array}{c}34.21 \pm 3.16 \\
26.23 \pm 3.21^{\prime \prime} \\
29.52 \pm 3.76 \\
25.17 \pm 3.35^{\pi} \\
22.14 \pm 3.27^{\star \pi}\end{array}$ & $\begin{array}{c}42.13 \pm 3.24 \\
33.37 \pm 2.57 \\
36.54 \pm 4.26 \\
33.29 \pm 3.92 \\
24.24 \pm 3.38^{\pi \pi}\end{array}$ \\
\hline
\end{tabular}

Compared with negative control group, $p<0.05, " p<0.01$.AME-L: $1.4 \mathrm{~g} / \mathrm{kg}$ of AME, AME-M: $2.8 \mathrm{~g} / \mathrm{kg}$ of AME, AME-H: $5.6 \mathrm{~g} / \mathrm{kg}$ of AME

\section{DISCUSSION}

Hemodynamic parameters are important markers which reflect cardiac functions. AME strengthened the diastolic and contractile functions of the artery and left ventricle, and significantly improved the left ventricular function with no change of heart rate.

Oxidative stress is one key factor for heart failure [16]. In heart failure, a large number of active oxygen families and nitric oxide are produced. In physiological state, the organism has an antioxidation system, for example SOD can clear away superoxide anions in time, and reduce lipid peroxidation. In physiological state, NO has the function of dilating blood vessels. However, NO does not only induce the production of free radicals, but also mediates serious neurotoxicity and cytotoxicity, thus promoting tissue injury. Synthesis of NO needs the participation of NOS [17]. AME significantly decreased blood MDA and NO levels, and CK and NOS activities but not blood SOD activity. Therefore, it is considered that the improvement of oxidative stress state by AME in CHF rats is not carried out by SOD.

\section{CONCLUSION}

The findings of this study indicate that AME improves chronic congestive heart failure in CHF rats, and this is probably linked to the alleviation of oxidative stress and improvement in left ventricular function. Thus, AME has the potential to be developed as an alternative medicine for treating chronic heart failure.

\section{DECLARATIONS}

\section{Conflict of interest}

No conflict of interest is associated with this work.

\section{Contribution of authors}

We declare that this work was done by the authors named in this article and all liabilities pertaining to claims relating to the content of this article will be borne by the authors. Lu Shi-juan designed all the experiment and revised the paper. Huang Kang, Zhong Jiang-hua, Wu Miao, Zhang Wei, Li Qiang and Xiang Qun performed the experiment, and Zhou Yi-lei and Wang Liu wrote the paper.

\section{Open Access}

This is an Open Access article that uses a funding model which does not charge readers or their institutions for access and distributed under the terms of the Creative Commons Attribution License (http://creativecommons.org/licenses/by/ 4.0) and the Budapest Open Access Initiative (http://www.budapestopenaccessinitiative.org/rea d), which permit unrestricted use, distribution, 
and reproduction in any medium, provided the original work is properly credited.

\section{REFERENCES}

1. Dickstein K, Cohen-Solal A, Filippatos G. Guidelines for the diagnosis and treatment of acute and chronic heart failure. Eur J Heart Fail 2008; 10: 933-989.

2. Hunt SA, Abraham WT, Chin MH, Feldman AM. ACC/AHA 2005 guideline update for the diagnosis and management of chronic heart failure in the adult a report of the American College of Cardiology/American Heart Association Task Force on Practice Guidelines. Circulation 2005; 112: e154-e235.

3. Gu D, Huang G, He J. Investigation of prevalence and distributing feature of chronic heart failure in Chinese adult population. Chin J Cardiol 2002; 31: 3-6.

4. McMurray J, Stewart $S$. The burden of heart failure. Eur Heart J 2002; 4: 50-58.

5. Costanzo MR, Guglin ME, Saltzberg MT. Ultrafiltration versus intravenous diuretics for patients hospitalized for acute decompensated heart failure. J Am Coll Cardiol 2007; 49: 675-683.

6. Yusuf $S$, Sleight $P$, Pogue J. Effects of an angiotensinconverting-enzyme inhibitor, ramipril, on cardiovascular events in high-risk patients. The Heart Outcomes Prevention Evaluation Study Investigators. N Engl $J$ Med 2000; 342: 145-153.

7. López-Sendó J, Swedberg K, McMurray J. Expert consensus document on $\beta$-adrenergic receptor blockers The Task Force on Beta-Blockers of the European Society of Cardiology. Eur Heart J 2004; 25: 1341-1362.

8. Torabi A, Cleland JG, Khan NK. The timing of development and subsequent clinical course of heart failure after a myocardial infarction. Eur. Heart J. 2008; 29: 859-870.

9. Chen J, Yao Y, Chen H. Shengmai (a traditional Chinese herbal medicine) for heart failure. Cochrane Database Syst. Rev 2012; 11: 41-43.

10. Tan G, Liao W, Dong X, Yang G. Metabonomic profiles delineate the effect of traditional Chinese medicine Sini decoction on myocardial infarction in rats. Plos One 2012; 7: e34157.

11. Liang X, Chen X, Liang Q, Zhang H. Metabonomic study of Chinese medicine Shuanglong formula as an effective treatment for myocardial infarction in rats. J Proteome Res 2010; 10: 790-799.

12. Fu S, Zhang J, Menniti-Ippolito F, Gao X. Huangqi injection (a traditional Chinese patent medicine) for chronic heart failure: A systematic review. Plos One 2011; 6: e19604.

13. Yong Chen. Clinical observation on the treatment of 50 cases of chronic heart failure with modified Zhenwu Decoction. Guangming Tradit Chin Med 2006; 21: 3436.

14. Zhu BB, Guo W, Huang L, Yang J. Effect of Zhenwu Decoction on ET and CGRP levels in chronic congestive heart failure model rats. Hubei Tradit Chin Med 2005; 26: 49-51.

15. European Commission [homepage on the internet]. Directive 2010/63/EU on the protection of animals used for scientific purposes [cited 2013 Jan 16]. Availablefrom:http://ec.europa.eu/environment/chemical s/lab_animals/legislation_en.htm.

16. Seddon $M$, Looi $Y H$, Shah AM. Oxidative stress and redox signalling in cardiac hypertrophy and heart failure. Heart 2006; 12: 131-138.

17. Azevedo PS, Minicucci MF, Santos PP. Energy metabolism in cardiac remodeling and heart failure. Cardiol Rev 2013; 21: 135-140. 